\title{
Ontomorphogenesis and life form of endemic the Pamiro-Alai Ziziphora Interrupta Juz. (Lamiaceae)
}

\author{
Kobil A. Bobokalonov ${ }^{I}$,Vera A. Cheryomushkina ${ }^{2 *}$, and Mariyo T. Boboev ${ }^{3}$ \\ ${ }^{1}$ Institute of Botany, Physiology and Plant Genetics, AS RT, Dushanbe, Tajikistan \\ ${ }^{2}$ Central Siberian Botanical Garden SB RAS, 630090 Novosibirsk, Russia \\ ${ }^{3}$ Khatlon Science centre AS RT 735360 Kulyab, Tajikistan
}

\begin{abstract}
The results are obtained which expand understanding of the semi-woody plant structure. Ontomorphogenesis and life form of Ziziphora interrupta Juz., growing in Tajikistan, were studied. It was established that the ontogenesis of individuals is simple, incomplete, its duration is at least 14-16 years. The multivariance of ontogenesis is revealed, expressed in the rates of development and omissions of ontogenetic states. The description of the formation shoot showed that the individual is characterized by a basisympodial growth and the formation of the life form of a dwarf subshrub.
\end{abstract}

Among the diversity of plant life forms, the semi-wood group is the least studied. There are no unambiguous criteria for the separation of subshrubs and dwarf subshrubs. The structural organization and morphogenesis of semi-woody plants has not been studied enough. A description of these life forms is impossible without studying the development of individuals in ontogenesis [1-4]. Of particular interest in this regard are species of the genus Ziziphora L., they play a significant role in the vegetation cover of the arid mountains of Central Asia. Most members of the genus are semi-woody plants. Information about their life form is mainly reflected in floristic reports, which are often contradictory [5-8]. Studies on the development of individuals of Ziziphora species are single [9-10].

Ziziphora interrupta Juz. is endemic of the Pamir-Alai. The range Z. interrupta is located within the Pamir-Alai and Tien Shan mountain systems. The northern part of the range passes along the Turkestan ridge, the southwest - along the Surkhan-Darya river valley, the western - along the Gissar ridge. In the east and south, the border runs through the Western Pamirs [5, 8]. In Tajikistan, the species is found in almost all floristic regions and is widespread in the belts of shibliak, blackforest, juniper, large-grass half-savanna, steppes, and prickly grasses; common in the formations of almonds, yuganniks, toronniks, wormwoods, ephedra, on stony-gravel and clayish talus slopes at an altitude of 700-2400 m $[5,7]$. There is no unequivocal opinion in the literature about the life form of $Z$. interrupta. This species is characterized as a high subshrub [5, 7], dwarf subshrub [8] or herb perennial

* Corresponding author: cher.51@mail.ru 
[6]. No one has previously studied the developmental features and structure of adult individuals of the species.

The aim is to study of ontomorphogenesis and description of the life form of Ziziphora interrupta in Tajikistan.

Material was collected in 2017-2018 on the Gissar ridge, in the Ramit river valley, in the shibliak belt on a stony-cobble slope, altitude $1400 \mathrm{~m}$. When determining the life form, the ecologo-morphological classification of life forms by I. G. Serebryakov [1] and approaches to the description of semi-woody plants [3] were used. Ontomorphogenesis was studied according to the approaches developed by A. A. Uranov and his progeny [11]. The shoots were characterized according to the terminology of M. T. Mazurenko and A. P. Khokhryakov [12]. The absolute age of individuals was determined by the annual rings on the roots, and the life span of the skeletal axes by the annual rings in their basal part.

In ontogenesis, individuals pass 2 phases of morphogenesis: the primary shoot and the primary bush. The first phase is very short, during this period the individual is in a state of seedling $(p)$ and juvenile $(j)$ plant. During most of the ontogenesis, the plant is in the "primary bush" phase.

As a rule, seeds begin to germinate during heavy rains in late November - early December. Seed germination aboveground. A hypocotyl $0.6 \mathrm{~cm}$ long carries elliptical cotyledons above the soil surface, then as a result of the development of the apical bud, 1-2 short metameres with oppositely located green leaves are formed. In the axils of the cotyledonary and true leaves, buds are laid. The height of the aerial part of the seedling does not exceed 1-1.5 cm. The length of the main root reaches $3 \mathrm{~cm}$. In December, the plants leave in winter with green leaves. The apical bud is open. By spring, cotyledon leaves die off. The individuals pass on a juvenile state. In the spring, in late February early March, the apical bud of the primary shoot starts to grow. Within a month, 3-4 short and 1-2 long metameres are formed, bearing decussate green leaves $0.9 \pm 0.02 \mathrm{~cm}$ long and $0.4 \pm 0.4 \mathrm{~cm}$ wide on average. Last year's leaves gradually turn yellow and die. The shoot height reaches $8-10 \mathrm{~cm}$. The length of the main root is $5.4 \pm 0.1 \mathrm{~cm}$. Some seeds germinate in the spring. In this case, the duration of the "primary shoot" phase is reduced to $1.5-2$ weeks (Fig.1.).

The primary shoot, while continuing to grow monopodially, its meristem separates 4-6 long metamers. In the axils of the leaves, buds are laid. Along with the growth of the primary shoot, axillary buds are revealed in the metameric nodes of last year's annual growth. 1-3 shoots up to $0.5-1 \mathrm{~cm}$ long are formed, consisting of 2-3 short metamers bearing green leaves. A primary bush is formed, and individuals pass into a virginal state (v). The main root branches weakly to the second order, lengthens to $7.6 \pm 0.12$, its diameter in the basal part reaches $0.3 \pm 0.02 \mathrm{~cm}$ on average. The basal parts of the main shoot and the main root begin to wood. The virginal state lasts 3-4 weeks.

In the same year, in early June, plants bloom and turn into a young generative state $\left(g_{l}\right)$. The primary shoot ends with an inflorescence - an intermittent spike-like thyrse, consisting of 2-3 opposite polynomial dichasia. In the axils of most green leaves on long metamers, buds open, forming vegetative enriching shoots consisting of 1-3 metamers. The green leaves that arose in the spring turn yellow and gradually die off. After flowering, the primary shoot becomes anisotropic, but does not take root. The plagiotropic part is located above the surface of the substrate, orthotropic part along with the inflorescence and enriching shoots dries in autumn. The plagiotropic part of the primary shoot and the basal part of the lateral shoots of the order II are woody and covered with a secondary ground tissue. In winter, individuals leave with lateral shoots of the order II, bearing green leaves for 2-3 short and 1-2 long metameres, and open lateral buds located on the living plagiotropic part of the primary shoot. Part of the buds become dormant. The following year, the apical bud of lateral shoots of the order II unfolds into a one-year generative long 
shoot. Monopodial growth of the individual is replaced by a sympodial. The primary bush consists of 2-3 dicyclic generative shoots of the order II and 1-3 monocyclic generative shoots deployed from wintering open buds. As in the previous year, shoots of the second order branch out, forming 2-3 lateral shoots of the third order up to 1-2 $\mathrm{cm}$ long (the first annual growth of dicyclic shoots). At the end of the growing season, the monocyclic shoots completely dry up, and the dicyclic shoots lie down, and their plagiotropic part carries shoots of the order III and lateral buds open to varying degrees, from which monocyclic generative shoots will unfold next year. Thus, the primary bush in a young generative state consists of perennial remnants of the primary shoot and second-order shoots that carry 2-3 generative dicyclic and 1-3 generative monocyclic shoots $26.9 \pm 0.27 \mathrm{~cm}$ high. Unrealized buds become dormant. The root system is mixed. The main root lengthens up to $9 \mathrm{~cm}$, its diameter is $0.4 \pm 0.05 \mathrm{~cm}$. In the basal part of the bush, adventitious roots are formed. The duration of the state is $2-3$ years.

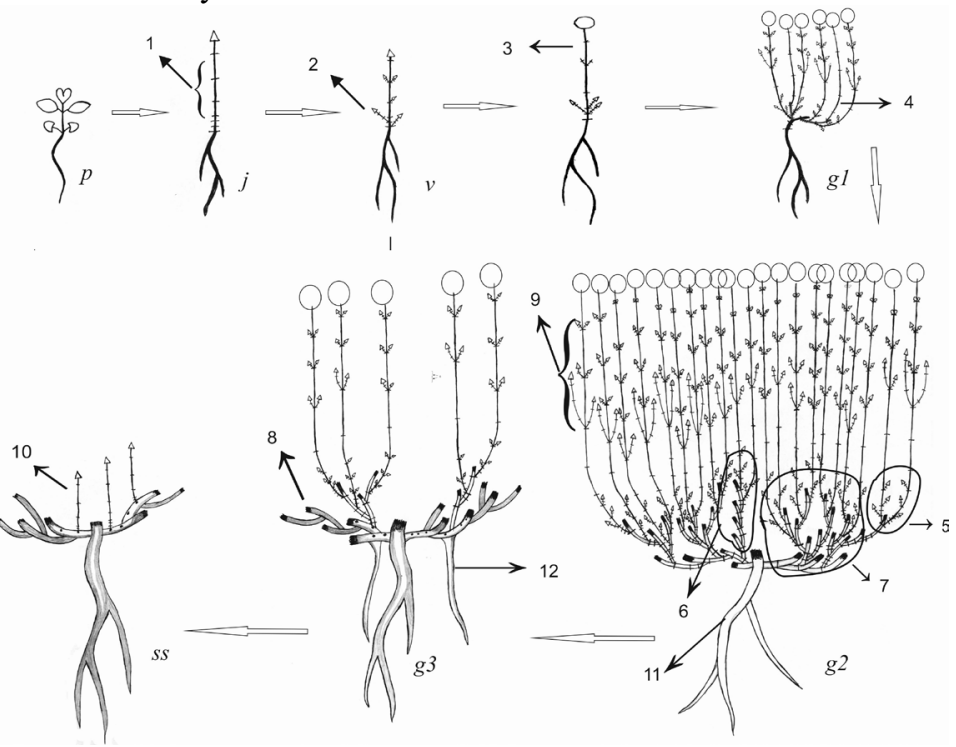

Fig. 1. Ontogenesis of Ziziphora interrapta. Ontogenetic states: $p$ - seedling, $j$ - juvenile, $v$ - virginal, $g_{1}$ - young generative, $g_{2}$ - mature generative, $g_{3}$ - old generative, $s s$ - subsenile; 1 - vegetative shoot, 2 - annual growth of the dicyclic generative shoot, 3 - dicyclic generative shoot, 4 - monocyclic generative shoot, 5- formation shoots, 6 - orthotropic skeletal axis, 7 - plagiotropic skeletal axis, 8 dead skeletal axis, 9 - enriching shoots, 10 -monocyclic vegetative shoot, 11 - main root, 12 secondary root

The plant passes into the mature generative state $\left(g_{2}\right)$ in the 3-4th year. Further development of individuals is associated with the formation of branched skeletal axes from dormant buds of the first annual growth of the primary shoot and dicyclic shoots of the second and third orders. The annual growth is $4-6 \mathrm{~cm}$ long, consists of 1-3 short $0.2-0.4$ $\mathrm{cm}$ in size and 2-3 long metameres $0.8-1.5 \mathrm{~cm}$ in size, at the nodes of which the buds are laid. By autumn, the shoot is lignified. In winter, he leaves with an open apical bud and green leaves in the apical part. In the second year, an orthotropic elongated part of the shoot develops, consisting of 14-18 metameres. From the buds of the lower and middle metamers of the second annual growth, poorly developed vegetative enriching shoots from 1 to $10 \mathrm{~cm}$ in length are deployed. In the distal part of the shoot, paracladia are formed, ending, like the primary shoot, with an inflorescence. Synflorescence is a raceme from opposite spike-like thyrsus. The length of paracladia varies from bottom to top along the shoot from $10 \mathrm{~cm}$ to 3 $\mathrm{cm}$. The shoot dries out completely until the first annual growth, which becomes a link in 
the skeletal axis. The branched skeletal axis grows sympodially in the type of dichasia, less commonly monochasia or pleochasia. Dicyclic the formation shoots of the following order are formed from wintering buds of long metamers of the first annual growth. Further growth of the skeletal axis and its branching can occur both due to buds located in the axil of long and short metameres of the first annual growth of the formation shoot of the previous order. Moreover, the higher the order of branching, the more long metameres are formed. Unrealized buds become dormant. Monocyclic generative shoots can be deployed from them. Dicyclic shoots up to the 8th order of branching take part in the construction of the skeletal axis, after which it dries up, but remains in the bush. Her life span is 6-9 years. The skeletal axis thickens in the basal part to $0.5 \mathrm{~cm}$

The branched skeletal axis is a sympodial system of branching dicyclic formation shoots of different orders. Dicyclic shoots are anisotropic. New skeletal axes are formed in the perennial basal part of the bush from dormant buds located on the primary and first annual growth of dicyclic shoots of the second and third orders. Depending on the position of the bud on the perennial part of the bush, the skeletal axis occupy an orthotropic or plagiotropic position and have different lengths and ages. Perennial orthotropic axes 10-20 $\mathrm{cm}$ long are located in the center of the bush; they are formed by growths of 4-5 shoots and increase densityof the bush. Plagiotropic axes carry assimilative generative shoots to the periphery of the bush, their length reaches $20-25 \mathrm{~cm}$. In individuals in this state, the maximum number of generative shoots is formed (from 20 to 100), their length is $42 \pm 0.3$ $\mathrm{cm}$. Thus, the height of the perennial part of the bush varies from $10 \mathrm{~cm}$ to $20 \mathrm{~cm}$, the height of the bush with annual shoots reaches $60 \mathrm{~cm}$, and its diameter is $50 \mathrm{~cm}$. The root system consists of a main root $13.3 \pm 0.1 \mathrm{~cm}$ long and $0.9 \pm 0.04 \mathrm{~cm}$ in diameter, 2-3 secondary roots located in the basal part of the bush and numerous ephemeral adventitious roots, developing both in the basal part of the bush and on the plagiotropic axes when they come into contact with the substratum or partially are covered with substratum. At the end of the ontogenetic state, partial particulation by parenchymal rays occurs, but the integrity of the skeletal axes and the main root is preserved. The duration of the mature generative state is $2-3$ years.

Old generative state $\left(g_{3}\right)$. The transition of plants to the old generative state is accompanied by a gradual drying of the skeletal axes, their preservation in the structure of the bush for some time, and then complete death and separation from the bush. Sometimes there is a complete particulation, capturing the main root. A clone is being formed. It consists of 2-3 particles, consisting of one or several branched skeletal axes and having secondary roots. New skeletal axes are not formed. Generative shoots develop from dormant buds of skeletal axes along the periphery of the bushes. The number and length of generative shoots are reduced $(12.1 \pm 0.3$ pcs. and $30.5 \pm 0.4 \mathrm{~cm}$, respectively). The central part of the plants loosens more and more. The length and diameter of the main root increase slightly $(15.7 \pm 0.4 \mathrm{~cm}$, and $1.3 \pm 0.04 \mathrm{~cm}$ respectively). The state lasts $2-3$ years.

Individuals in the subsenile state (ss) are characterized by an increase in the number of residues of dry skeletal axes, both along the periphery of the bushes and in their central part. Along the periphery and in the center of the bush, from dormant buds, up to 6-8 vegetative monocyclic shoots develop with a length of $7.4 \pm 0.3$. The duration of the postgenerative period is $1-2$ years. Senile state $(s)$ is absent. The total duration of ontogenesis is $14-17$ years.

A study of the formation shoot and structure of adult individuals showed that $Z$. interrupta forms the life form of a monocentric dwarf subshrub in the conditions of Tajikistan. The bush of an individual in the generative period consists of branched skeletal axes formed by the formation shoots of ever-increasing orders and their systems, and a branched main root. An individual is characterized by a basisympodial growth. Short orthotropic axes are located in the center of the bush, they increase its density. Long 
plagiotropic axes carry generative shoots to the periphery of the bush and contribute to the growth of the individual. In both cases, the buds of the dicyclic innovation shoots are located in their basal part at the first annual growth and are located no higher than $3-5 \mathrm{~cm}$ from the soil surface. According to the researchers [2, 3], plants with the innovation buds above the substrate and the basisympodial method of growth should be classified as dwarf subshrubs. Ontogenesis of individuals of $Z$. interrupta is simple, incomplete, pregenerative and postgenerative periods are short. The total duration of ontogenesis is 14-17 years. In the pregenerative period, multivariance of ontogenesis is observed, expressed as a absence of the immature state and acceleration of the development of young individuals until the onset of flowering in the year of seed germination. At the end of ontogenesis, senile particilation is possible. Self-maintenance of populations occurs exclusively by seed.

The work was carried out within the framework of the projects of State Assignments ГР № 01011ТД065 and 0116ТJ00762 (Tajikistan) and project of the State Assignment of Central Siberian Botanical Garden of the Siberian Branch of the Russian Academy of Sciences № AAAA-A17117012610053-9.

\section{References}

1. I. G. Serebryakov, Ecological morphology of plants (Sov. Nauka, Moscow, 1962).

2. L. N. Dorokhina, Biol. Science, 2, 53-58 (1970).

3. L. E. Gatsuk, Bul. MOIP. Otd. Biol. 79, 84-100 (1974).

4. A. A. Butnik, O. A. Ashurmetov, R. N. Nigmanova, S. A. Payzieva Ecological anatomy of desert plants of Central Asia. Shrubs and shrubs 2. (FAN, Tashkent, 2001).

5. S. V. Yuzepchuk, Flora of the SSSR 21, 386-404 (1954).

6. A. I. Vvedenskiy, Flora of the Uzbek SSR 5, 396-400 (1961).

7. T. F. Kochkareva, Flora of the Tajik SSR 8, 266-274 (1986).

8. M. Tulaganova, Key to plants of Central Asia 9, 155-159 (1987).

9. L. A. Kononenko, Ecology of plants of eroded slopes, 26-43 (1972).

10. V. A. Cheryomushkina, K.A. Bobokalonov, Rastitel'ny mir Aziatskoy Rossii, 2, 2533 (2020).

11. O. V. Smirnova, L. B. Zaugol'nova and etc, Coenopopulation of plants (Nauka, Moscow, 1976).

12. M. T. Mazurenko and A. P. Khokhryakov. Structure and morphogenesis of shrubs (Nauka, Moscow, 1977). 